DOI : 10.5050/KSNVE.2010.20.8.742

$$
\text { 가청화를 이용한 고소음 작업장의 흡음대책 평가 }
$$

\title{
Evaluation on Attenuation for Sound-absorbing Measures of Loud Noisy Work-site using Auralizational Technique
}

\author{
윤 재 현*. 김 재 수† \\ Jae-Hyun Yun and Jae-Soo Kim \\ (2010년 6월 1일 접수 ; 2010년 7월 29일 심사완료)
}

Key Words : Sound-absorption Measure(흡음대책), Acoustic Simulation(음향시뮬레이션), Auralization(가청화), Psycho-acoustics Experiment(청감실험)

\begin{abstract}
In case of the working machine that using in the loud-noisy workplace, as it generates the loud-noise, it is influencing a physical, mental bad effect to those workers. Accordingly, though the noise countermeasure for the loud-noisy workplace is acutely requiring, until now, those methods that wearing the soundproof-protection tool, or restriction the working hours, and minimize the noise exposure volume, were mainly used. However, such noise countermeasures occur many problem points. On such point of view, using the acoustic simulation technique, let the workers to choose the workplace where suffering many damages due to the noise of working machine, and after grasp the physical property of working machine and indoor acoustic characteristic, this Study has attempted to grasp the reduction degree of noise level at before-improvement-after-improvement, through the sound-absorption measure. Passing through such preceding step, using auralizational technique based on the noise of working machine of before-improvement-after-improvement, and by conduct psycho-acoustics evaluation, this study intended to investigate the change degree of subject reaction. As the result of evaluation, it is considering that the noise-reduction countermeasure method for the loud-noisy workplace could be much effective, through the sound-absorption measure.
\end{abstract}

\section{1. 서 론}

산업혁명 이후 다양한 작업기계가 발명되면서 노 동력과 시간을 줄일 수 있게 되었다. 그러나 고소음 작업장에서 사용하는 작업기계의 경우 고소음을 발 생시켜 작업자들에게 신체적, 정신적 악영향을 미치 고 있다. 따라서 고소음 작업장의 소음대책이 절실

† 교신저자; 정회원, 원광대학교 건축공학과

E-mail : soundpro@wonkwang.ac.kr

Tel : (063)850-5712, Fax : (063)843-07820

* 정회원, 원광대학교 건축음향연구실
히 필요하나 지금까지는 방음보호구를 착용하거나 작업시간을 제한하여 소음 노출량을 최소화하는 방 법을 주로 사용하였다. 그러나 이러한 소음대책은 소극적이고 영구적이지 않으므로 많은 한계를 가지 고 있으며, 또한 작업자에게 보호구 착용으로 인한 불편함과 작업시간 제한에 따른 생산성 저하를 초 래하는 등의 문제를 발생시킨다. 이러한 관점에서 이 연구는 음향시뮬레이션 기법을 이용 ${ }^{(1)}$ 하여 작업 자로 하여금 작업기계의 소음으로 인하여 많은 피 해를 받고 있는 작업장(보석 가공장, 모형 공작실) 을 선정하여, 현재 사용하고 있는 작업기계의 물리 
적 특성을 파악하였다. 또한 시뮬레이션과의 신뢰성 확보를 위해 실내 음향상태를 측정한 뒤 동일한 음 향상태를 갖는 작업장을 모델링 한 후 흡음대책을 통해 개선 전·후의 소음레벨 저감정도를 파악하고 자 하였다. 이러한 선행단계를 거쳐 가청화 기법을 이용하여 개선 전·후의 작업기계 소음을 바탕으로 청감평가를 실시하여 주관적 반응 변화 정도를 조 사다하고자 하였다. 이러한 자료는 연구대상 고소음 작업장과 유사한 작업장의 소음저감대책 시 유용한 자료로 활용될 수 있을 것으로 사료된다.

\section{2. 개요 및 측정방법}

\section{1 연구대상 고소음 작업장의 개요}

측정대상 작업장 제원 및 마감 재료의 주파수별
흡음률은 Tables 1, 2와 같으며, 노동부 고시 제 2005-1-49(작업환경측정 및 정도관리규정, 전문개정 2005. 12. 30)에 제 26조 측정방법에 측정된 작업 장별 작업기계의 음압레벨은 Table $3^{(3,4)}$ 과 같다.

Tables 1,2 를 보면 대상 작업장의 경우 $500 \mathrm{~m}^{3}$ 이 하의 협소한 공간에서 작업이 이루어지고 있으며, 주 요 구조부인 바닥, 벽, 천장의 $500 \mathrm{~Hz}$ 흡음률이 $\alpha$ $=0.01 \sim 0.16$ 인 반사성이 강한 마감 재료를 사용한

Table 1 Dimension of the object loud-noisy workplace

\begin{tabular}{c|c|c}
\hline \hline Loud-noisy workplace & $\begin{array}{c}\text { Indoor surface } \\
\text { area(S) }\end{array}$ & $\begin{array}{c}\text { Indoor } \\
\text { volume(V) }\end{array}$ \\
\hline Jewelry processing room & $114.4 \mathrm{~m}^{2}$ & $434.72 \mathrm{~m}^{3}$ \\
\hline Model making room & $61.2 \mathrm{~m}^{2}$ & $177.5 \mathrm{~m}^{3}$ \\
\hline
\end{tabular}

Table 2 Finishing material at before-improvement of the object loud-noisy workplace

\begin{tabular}{|c|c|c|c|c|c|c|c|c|}
\hline \multirow{2}{*}{$\begin{array}{l}\text { Loud-noisy } \\
\text { workplace }\end{array}$} & \multirow{2}{*}{ Location } & \multirow{2}{*}{ Material } & \multicolumn{6}{|c|}{ Frequency $(\mathrm{Hz})$} \\
\hline & & & 125 & 250 & 500 & $1 \mathrm{k}$ & $2 \mathrm{k}$ & $4 \mathrm{k}$ \\
\hline \multirow{5}{*}{$\begin{array}{c}\text { Jewelry processing } \\
\text { room }\end{array}$} & Floor & Imitation stone finishing & 0.02 & 0.02 & 0.02 & 0.03 & 0.04 & 0.04 \\
\hline & Wall & $\begin{array}{l}\text { Water-based paint finish } \\
\text { on the cement }\end{array}$ & 0.01 & 0.01 & 0.02 & 0.02 & 0.02 & 0.03 \\
\hline & Ceiling & 9T sound-absorption tex & 0.30 & 0.20 & 0.16 & 0.12 & 0.15 & 0.20 \\
\hline & Door & Common wooden door & 0.14 & 0.10 & 0.06 & 0.05 & 0.10 & 0.10 \\
\hline & Window & Ordinary glass window & 0.35 & 0.25 & 0.18 & 0.12 & 0.07 & 0.04 \\
\hline \multirow{5}{*}{$\begin{array}{l}\text { Model making } \\
\text { room }\end{array}$} & Floor & Imitation stone finishing & 0.02 & 0.02 & 0.02 & 0.03 & 0.04 & 0.04 \\
\hline & $\begin{array}{c}\text { Wall } \\
\text { Ceiling }\end{array}$ & $\begin{array}{l}\text { Water-based paint finish } \\
\text { on the cement }\end{array}$ & 0.01 & 0.01 & 0.02 & 0.02 & 0.02 & 0.03 \\
\hline & Door & Common wooden door & 0.14 & 0.10 & 0.06 & 0.05 & 0.10 & 0.10 \\
\hline & Window & Ordinary glass window & 0.35 & 0.25 & 0.18 & 0.12 & 0.07 & 0.04 \\
\hline & Partition & Sandwich panel & 0.01 & 0.01 & 0.01 & 0.02 & 0.02 & 0.02 \\
\hline
\end{tabular}

Table 3 Sound pressure level of working machine by each workplace

\begin{tabular}{|c|c|c|c|c|c|c|c|c|c|c|c|}
\hline \multirow{2}{*}{ Workplace } & \multirow{2}{*}{ Working machine } & \multirow{2}{*}{\begin{tabular}{|c|} 
Electric \\
power
\end{tabular}} & \multicolumn{8}{|c|}{ Frequency $(\mathrm{Hz})$} & \multirow{2}{*}{$\begin{array}{l}\mathrm{dB} \\
\text { (A) }\end{array}$} \\
\hline & & & 63 & 125 & 250 & 500 & $1 \mathrm{k}$ & $2 \mathrm{k}$ & $4 \mathrm{k}$ & $8 \mathrm{k}$ & \\
\hline \multirow{5}{*}{$\begin{array}{l}\text { Jewelry } \\
\text { processing } \\
\text { room }\end{array}$} & Jewelry grinder & $0.2 \mathrm{~kW}$ & 58.0 & 68.2 & 66.8 & 68.0 & 70.9 & 69.3 & 60.9 & 59.6 & 74.3 \\
\hline & Facet grinder & $0.2 \mathrm{~kW}$ & 67.9 & 68.1 & 65.3 & 63.8 & 66.5 & 69.5 & 66.7 & 61.9 & 74.4 \\
\hline & Rock cutter & $0.35 \mathrm{~kW}$ & 86.6 & 92.0 & 65.7 & 70.0 & 67.8 & 71.5 & 71.3 & 59.5 & 79.2 \\
\hline & Gloss grinder & 84.4 & 77.1 & 86.6 & 80.9 & 80.5 & 80.9 & 81.4 & 77.1 & 88.2 & 80.9 \\
\hline & Minute jewelry grinder & $0.45 \mathrm{~kW}$ & 61.4 & 62.4 & 68.2 & 67.9 & 73.5 & 77.2 & 71.0 & 64.5 & 82.3 \\
\hline \multirow{8}{*}{$\begin{array}{l}\text { Model } \\
\text { making } \\
\text { room }\end{array}$} & Small drill & $0.08 \mathrm{~kW}$ & 56.2 & 61.0 & 50.1 & 62.4 & 63.3 & 56.9 & 54.0 & 49.4 & 66.0 \\
\hline & Disk sander & $0.1 \mathrm{~kW}$ & 63.4 & 67.1 & 61.2 & 62.7 & 56.8 & 62.3 & 58.6 & 59.8 & 67.5 \\
\hline & $\begin{array}{l}\text { Middle- typed table } \\
\text { circular saw }\end{array}$ & $0.4 \mathrm{~kW}$ & 62.2 & 79.7 & 74.4 & 69.4 & 64.1 & 58.5 & 56.2 & 49.3 & 71.9 \\
\hline & Middle- typed circular saw & $0.2 \mathrm{~kW}$ & 61.4 & 74.7 & 60.7 & 57.8 & 69.1 & 61.6 & 66.4 & 46.7 & 72.3 \\
\hline & Table squash saw & $1.0 \mathrm{~kW}$ & 48.1 & 64.7 & 66.5 & 75.4 & 70.6 & 62.2 & 67.3 & 68.1 & 76.3 \\
\hline & Table band saw machine & $0.2 \mathrm{~kW}$ & 50.5 & 51.0 & 47.9 & 53.6 & 72.6 & 73.6 & 63.3 & 53.8 & 77.2 \\
\hline & Small circular saw & $0.08 \mathrm{~kW}$ & 71.9 & 74.7 & 57.2 & 68.2 & 69.3 & 77.0 & 89.8 & 91.3 & 94.4 \\
\hline & Machine electric plane & $0.5 \mathrm{~kW}$ & 58.6 & 76.6 & 86.3 & 90.9 & 93.1 & 92.7 & 90.9 & 87.7 & 98.6 \\
\hline
\end{tabular}


Table 4 NR and decided frequency of working machine by each workplace

\begin{tabular}{|c|c|c|c|}
\hline $\begin{array}{l}\text { Loud-noisy } \\
\text { workplace }\end{array}$ & Working machine & NR & $\begin{array}{c}\text { Decision } \\
\text { frequency } \\
(\mathrm{Hz})\end{array}$ \\
\hline \multirow{5}{*}{$\begin{array}{l}\text { Jewelry } \\
\text { processing } \\
\text { room }\end{array}$} & Jewelry grinder & NR-71 & 2,000 \\
\hline & Facet grinder & NR-72 & 2,000 \\
\hline & Rock cutter & NR-81 & 125 \\
\hline & Gloss grinder & NR-85 & 4,000 \\
\hline & Minute jewelry grinder & NR-79 & 2,000 \\
\hline \multirow{8}{*}{$\begin{array}{l}\text { Model } \\
\text { making } \\
\text { room }\end{array}$} & Small drill & NR-63 & 1,000 \\
\hline & Disk sander & NR-66 & 8,000 \\
\hline & $\begin{array}{l}\text { Middle-typed table } \\
\text { circular saw }\end{array}$ & NR-66 & 125 \\
\hline & $\begin{array}{l}\text { Middle-typed circular } \\
\text { saw }\end{array}$ & NR-70 & 4,000 \\
\hline & Table squash saw & NR-74 & 8,000 \\
\hline & $\begin{array}{l}\text { Table band saw } \\
\text { machine }\end{array}$ & NR-75 & 2,000 \\
\hline & Small circular saw & NR-96 & 8,000 \\
\hline & Machine electric plane & NR-95 & 4,000 \\
\hline
\end{tabular}

Table 5 Finishing material at after-improvement of the object loud-noisy workplace

\begin{tabular}{|c|c|c|c|c|c|c|c|c|}
\hline \multirow{2}{*}{$\begin{array}{l}\text { Loud-noisy } \\
\text { workplace }\end{array}$} & \multirow{2}{*}{ Location } & \multirow{2}{*}{$\begin{array}{c}\text { Finishing } \\
\text { material }\end{array}$} & \multicolumn{6}{|c|}{ Frequency(Hz) } \\
\hline & & & 125 & 250 & 500 & $1 \mathrm{k}$ & $2 \mathrm{k}$ & $4 \mathrm{k}$ \\
\hline \multirow{5}{*}{$\begin{array}{c}\text { Jewelry } \\
\text { processing } \\
\text { room }\end{array}$} & Floor & $\begin{array}{l}\text { Imitation } \\
\text { stone } \\
\text { finishing }\end{array}$ & 0.02 & 0.02 & 0.02 & 0.03 & 0.04 & 40.04 \\
\hline & Wall & $\begin{array}{c}12 \mathrm{~T} \text { rock } \\
\text { wool } \\
\text { sound-absorpt } \\
\text { ion panel }\end{array}$ & 0.20 & 0.20 & 0.40 & 0.60 & 0.70 & 0.75 \\
\hline & Ceiling & $\begin{array}{c}\text { Sound-absorp } \\
\text { tion ceiling } \\
\text { panel }\end{array}$ & 0.55 & 0.55 & 0.58 & 0.63 & 0.68 & 0.59 \\
\hline & Door & $\begin{array}{c}\text { Soundproof } \\
\text { door }\end{array}$ & 0.06 & 0.13 & 0.10 & 0.10 & 0.10 & 0.10 \\
\hline & Window & $\begin{array}{c}\text { Double pane } \\
\text { window }{ }^{+} \\
\text {curtain }^{2}\end{array}$ & 0.15 & 0.25 & 0.50 & 0.75 & 0.80 & 0.85 \\
\hline \multirow{6}{*}{$\begin{array}{l}\text { Model } \\
\text { making } \\
\text { room }\end{array}$} & Floor & $\begin{array}{l}\text { Imitation } \\
\text { stone } \\
\text { finishing }\end{array}$ & 0.02 & 0.02 & 0.02 & 0.03 & 0.04 & 40.04 \\
\hline & Wall & $\begin{array}{c}\text { 12T rock } \\
\text { wool } \\
\text { sound-absorpt } \\
\text { ion pane1 }{ }^{1)}\end{array}$ & 0.20 & 0.20 & 0.40 & 0.60 & 0.70 & 0.75 \\
\hline & Ceiling & $\begin{array}{c}\text { Sound-absorp } \\
\text { tion ceiling } \\
\text { panel }\end{array}$ & 0.55 & 0.55 & 0.58 & 0.63 & 0.68 & 0.59 \\
\hline & Door & $\begin{array}{l}\text { Soundproof } \\
\text { door }\end{array}$ & 0.06 & 0.13 & 0.10 & 0.10 & 0.10 & 0.10 \\
\hline & Window & $\begin{array}{c}\text { double pane } \\
\text { window }{ }^{+} \\
\text {curtain }^{2)}\end{array}$ & 0.15 & 0.25 & 0.50 & 0.75 & 0.80 & 0.85 \\
\hline & Partition & $\begin{array}{c}\text { Sandwich } \\
\text { panel }\end{array}$ & 0.01 & 0.01 & 0.01 & 0.02 & 0.02 & 0.02 \\
\hline
\end{tabular}

1) Space of the basement $0.7 \mathrm{~m}$ is existing same

2) Wrinkles curtain $50 \%$
것을 알 수 있다. 또한 Table 3 을 보면 각 작업장에 서 사용하는 작업기계의 음압레벨은 $66.0 \sim 98.6$ $\mathrm{dB}(\mathrm{A})$ 로 매우 높게 나타났다. 이러한 결과로 미루 어 볼 때 대상 고소음 작업장의 경우 반사성이 강 한 마감 재료로 인하여 높은 음압레벨를 갖는 작업 기계 소음이 내부 공간에서 더욱 증폭되어 작업자 로 하여금 신체적·정신적 악영향을 미칠 것으로 사 료된다.

\subsection{NR곡선에 의한 평가}

이 연구에서는 대상 고소음 작업장의 흡음대책을 위해 ISO에서 제안하는 NR평가 방법을 이용하였다. $\mathrm{NR}$ 곡선(noise rating curves)은 소음을 청력장해, 회화 방해, 시끄러움의 3가지 관점에서 평가하여 1961년 ISO가 정한 소음평가 곡선으로 $1,000 \mathrm{~Hz}$ 의 옥타브밴 드 레벨이 평가곡선의 $\mathrm{NRN}$ (noise rating number)과 일치하고 있다. 이를 토대로 하여 각 작업장별 작업 기계의 주파수 분석된 결과를 $1 / 1$ 옥타브밴드로 하 여 NR곡선으로 평가해 본 결과는 Table 4와 같다.

Table 4를 보면 연구대상 작업장에서 사용하는 작업기계의 $\mathrm{NR}$ 등급 결정주파수가 대부분 1,000 $8,000 \mathrm{~Hz}$ 의 중 · 고음역대에서 결정되므로 이 주파수 대역에서 흡음 성능이 높은 마감 재료를 사용하여 소음 저감대책 수립을 하면 효과적일 것으로 사료 된다. 따라서 이 연구에서는 위와 같은 사항을 고려 하여 작업장의 특성에 알맞은 Table 5 와 같은 마감 재료의 개선안을 제안하였다.

\section{3 작업장의 잔향시간 측정}

작업장 잔향시간 측정의 경우 ISO 3382에 준하여 실시하였으며, 음원은 $\mathrm{ISO}$ 에서 제안하는 무지향성 스피커(DO12: omni-directional speaker)를 $1.5 \mathrm{~m}$ 높이 에 마이크로폰은 높이는 $1.2 \mathrm{~m}$ 로 하여 각 벽면과 최소 $1 \mathrm{~m}$ 이상 이격시켜 측벽 반사에 의한 영향이 미치지 않도록 하였다. 또한 시뮬레이션의 신뢰도를 높이기 위해 작업기계가 위치한 곳에 수음점을 선 정하여 측정을 실시하였다. 측정장비 구성 및 측정 장면과 측정위치는 Figs. 1, 2와 같다.

\subsection{Computer Simulation}

이 연구에서 사용된 프로그램은 Odeon ver. 4.21 이며, 실측된 잔향시간과의 정확한 비교를 위해 음원 

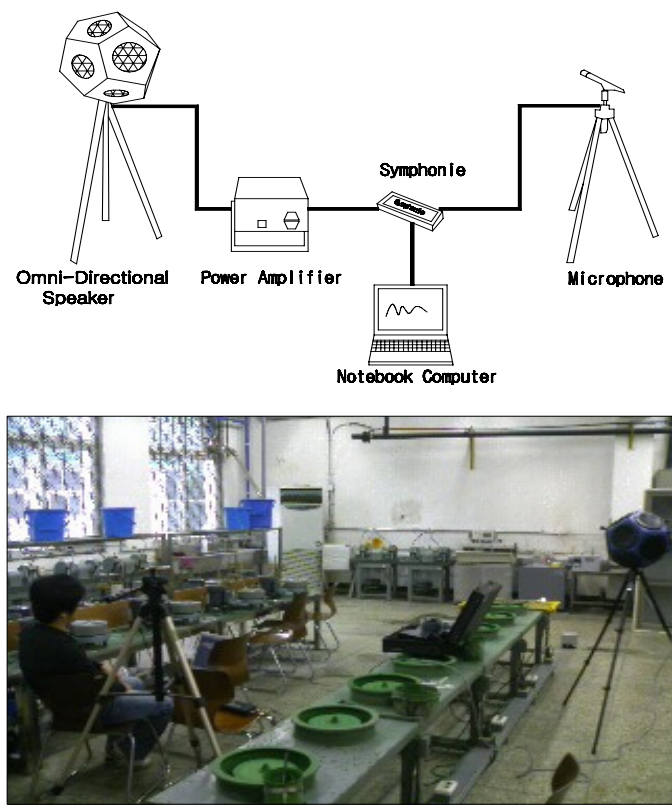

Fig. 1 Scene from psycho-acoustic experiment

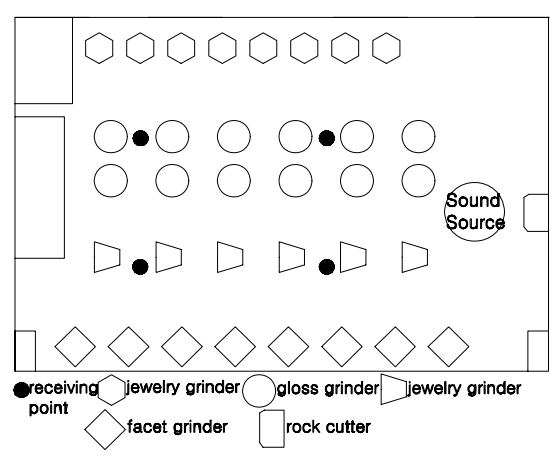

(a) Jewelry processing room

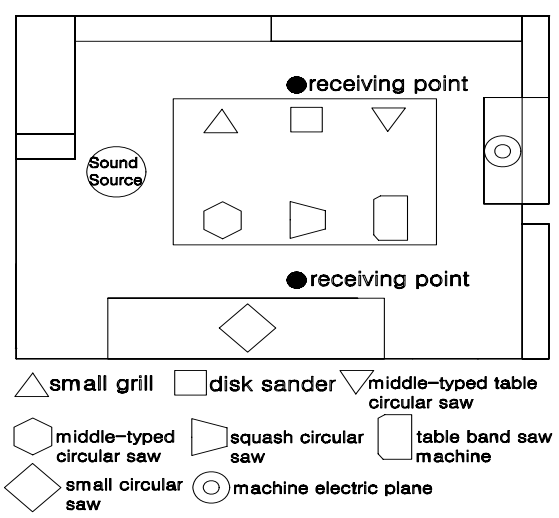

(b) Model making room

Fig. 2 One side and survey location of the object loud-noisy workplace

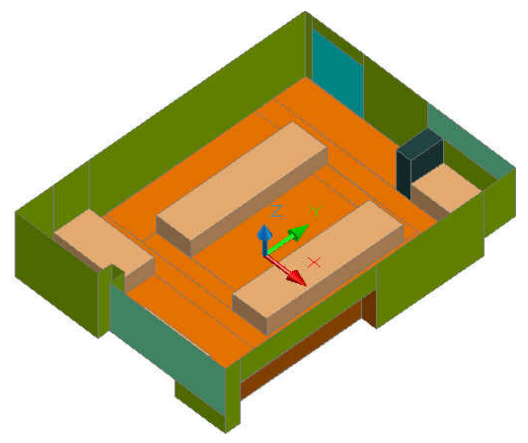

(a) Jewelry processing room

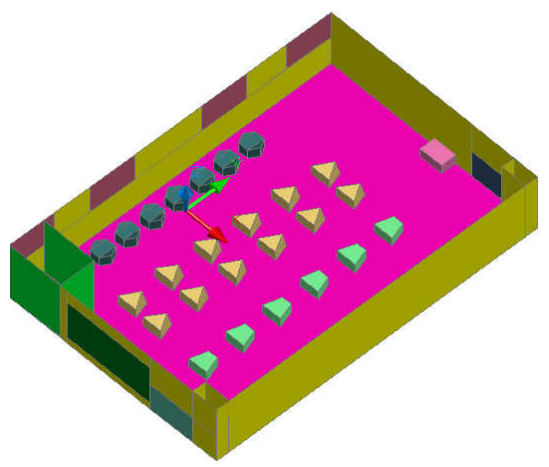

(b) Model making room

Fig. 3 3-dimensional modelling of the object loudnoisy workplace

및 수음점은 동일하게 설정하였다 ${ }^{(2)}$. 또한 작업장의 크기가 작기 때문에 impulse response 길이를 2,500 으로 하였으며, 온도 및 습도는 잔향시간 측정일과 동일하게 하였다. 위의 내용을 바탕으로 한 대상 작 업장의 3차원 모델링된 ${ }^{(6)}$ 모습은 Fig. 3 과 같다.

\section{3. 분석 및 고찰}

3.1 음향 시뮬레이션을 통한 개선 전 - 후 비교 (1) 실측된 잔향시간과 음향시뮬레이션과의 비교 작업장별로 실측된 잔향시간을 동일하게 모델링한 음향 시뮬레이션상의 예측값과 비교한 것은 Table 6 과 Fig. 4와 같다.

Table 6과 Fig. 4를 보면 실측치와 예측치의 결과 값이 거의 유사한 패턴을 보이고 있음을 알 수 있 다. 또한 보다 더 정확한 비교를 위해 0.9 이상이면 신뢰도를 확보하는 cronbach's $\alpha$ 계수를 이용하여 확인해본 결과 보석 가공장은 0.950 , 모형 공작실은 0.972의 높은 신뢰도로 나타났다. 따라서 시뮬레이 
션 예측치의 신뢰성을 확보하였다.

(2) 음압레벨(SPL) 비교

Table 5에서 제시한 마감 재료로 흡음대책을 세 운 후 실시 하였으며, 이때 작업기계별 음향파워레 벨 $(P W L=S P L+20 \log r+8$, 여기서 $r=$ 이격거리 $)$ 은 Table 7과 같다.

소음에 대한 최대 피해정도를 알아보기 위해 모든 작업기계가 동시에 작동한다는 가정하에 음향 시뮬레 이션을 실시하였으며, 음향 시뮬레이션을 통하여 나타 난 개선 전.후의 음압레벨 결과는 Table 8과 Fig. 5와 같다.

Table 6 Comparison actual measured value with RT of predicted value( $\mathrm{sec})$

\begin{tabular}{|c|c|c|c|c|c|c|c|c|c|}
\hline \multirow{2}{*}{$\begin{array}{c}\text { Loud- } \\
\text { noisy } \\
\text { workplace }\end{array}$} & \multirow{2}{*}{\multicolumn{2}{|c|}{ Comparison item }} & \multicolumn{7}{|c|}{ Frequency $(\mathrm{Hz})$} \\
\hline & & & 125 & 250 & 500 & $1 \mathrm{k}$ & $2 \mathrm{k}$ & $4 \mathrm{k}$ & $8 \mathrm{k}$ \\
\hline \multirow{2}{*}{$\begin{array}{c}\text { Jewelry } \\
\text { processing } \\
\text { room }\end{array}$} & \multirow{4}{*}{$\begin{array}{c}\text { Reverb } \\
\text { eration } \\
\text { time } \\
(\mathrm{RT})\end{array}$} & $\begin{array}{c}\text { Actual } \\
\text { measured } \\
\text { value }\end{array}$ & 1.55 & 1.67 & 1.64 & 1.67 & 1.67 & 1.52 & 1.23 \\
\hline & & $\begin{array}{c}\text { Predicted } \\
\text { value }\end{array}$ & 1.41 & 1.69 & 1.66 & 1.71 & 1.76 & 1.42 & 1.15 \\
\hline \multirow{2}{*}{$\begin{array}{l}\text { Model } \\
\text { making } \\
\text { room }\end{array}$} & & $\begin{array}{c}\text { Actual } \\
\text { measured } \\
\text { value }\end{array}$ & 0.67 & 0.59 & 0.55 & 0.48 & 0.41 & 0.41 & 0.41 \\
\hline & & $\begin{array}{l}\text { Predicted } \\
\text { value }\end{array}$ & 0.73 & 0.66 & 0.59 & 0.58 & 0.54 & 0.51 & 0.46 \\
\hline
\end{tabular}

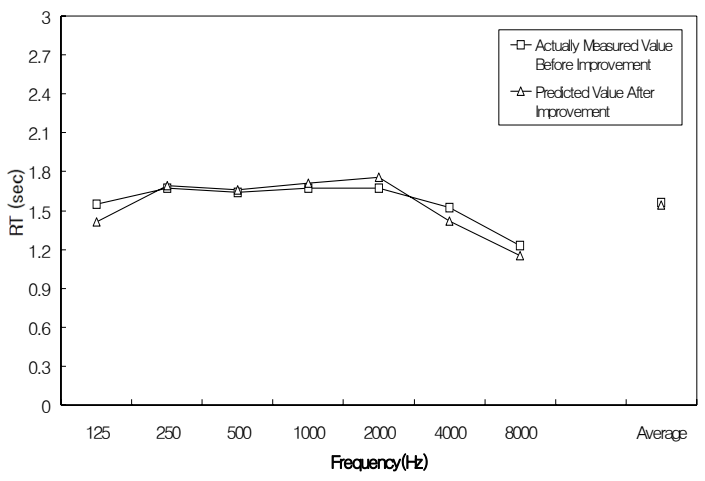

(a) Jewelry processing room

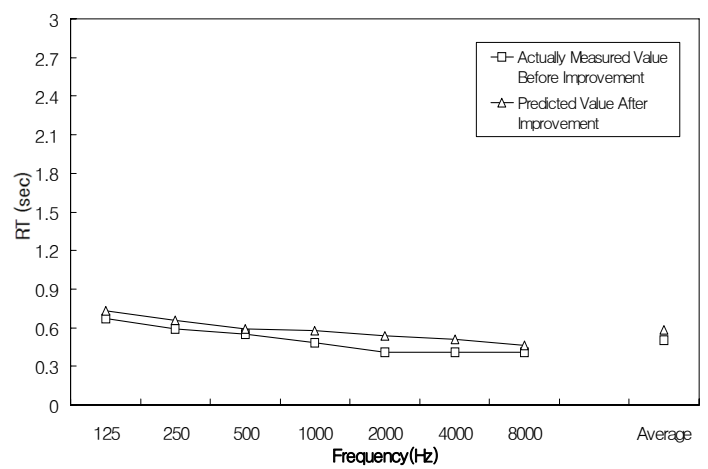

(b) Model making room

Fig. 4 (By frequency) Comparison actual measured value with RT of predicted value

Table 7 Working machine PWL by each workplace $(\mathrm{dB})$

\begin{tabular}{|c|c|c|c|c|c|c|c|c|c|}
\hline \multirow{2}{*}{ Workplace } & \multirow{2}{*}{ Working machine } & \multicolumn{8}{|c|}{ Frequency $(\mathrm{Hz})$} \\
\hline & & 63 & 125 & 250 & 500 & $1 \mathrm{k}$ & $2 \mathrm{k}$ & $4 \mathrm{k}$ & $8 \mathrm{k}$ \\
\hline \multirow{5}{*}{$\begin{array}{l}\text { Jewelry } \\
\text { processing } \\
\text { room }\end{array}$} & Jewelry grinder & 69.5 & 79.7 & 78.3 & 79.5 & 82.4 & 80.8 & 72.4 & 71.1 \\
\hline & Facet grinder & 79.4 & 79.6 & 76.8 & 75.3 & 78.0 & 81.0 & 78.2 & 73.4 \\
\hline & Rock cutter & 98.1 & 103.5 & 77.2 & 81.5 & 79.3 & 83.0 & 82.8 & 71.0 \\
\hline & Gloss grinder & 88.6 & 98.1 & 92.4 & 92.0 & 92.4 & 92.9 & 88.6 & 99.7 \\
\hline & Minute jewelry grinder & 72.9 & 73.9 & 79.7 & 79.4 & 85.0 & 88.7 & 82.5 & 76.0 \\
\hline \multirow{8}{*}{$\begin{array}{l}\text { Model making } \\
\text { room }\end{array}$} & Small drill & 67.7 & 72.5 & 61.6 & 73.9 & 74.8 & 68.4 & 65.5 & 60.9 \\
\hline & Disk sander & 74.9 & 78.6 & 72.7 & 74.2 & 68.3 & 73.8 & 70.1 & 71.3 \\
\hline & Middle-typed table circular saw & 73.7 & 91.2 & 85.9 & 80.9 & 75.6 & 70.0 & 67.7 & 60.8 \\
\hline & Middle-typed circular saw & 72.9 & 86.2 & 72.2 & 69.3 & 80.6 & 73.1 & 77.9 & 58.2 \\
\hline & Table squash saw & 59.6 & 76.2 & 78.0 & 86.9 & 82.1 & 73.7 & 78.8 & 79.6 \\
\hline & Table band saw mashine & 62.0 & 62.5 & 59.4 & 65.1 & 84.1 & 85.1 & 74.8 & 65.3 \\
\hline & Small circular saw & 83.4 & 86.2 & 68.7 & 79.7 & 80.8 & 88.5 & 101.3 & 102.8 \\
\hline & Machine electric plane & 70.1 & 88.1 & 97.8 & 102.4 & 104.6 & 104.2 & 102.4 & 99.2 \\
\hline
\end{tabular}


Table 8과 Fig. 5 를 보면 개선전에 비해 개선후 흡음력이 높은 마감 재료의 사용으로 인해 모든 주 파수의 음압레벨이 감소한 것을 알 수 있다. 또한 음압레벨의 경우 흡음되는 면적이 개선 전에 비해

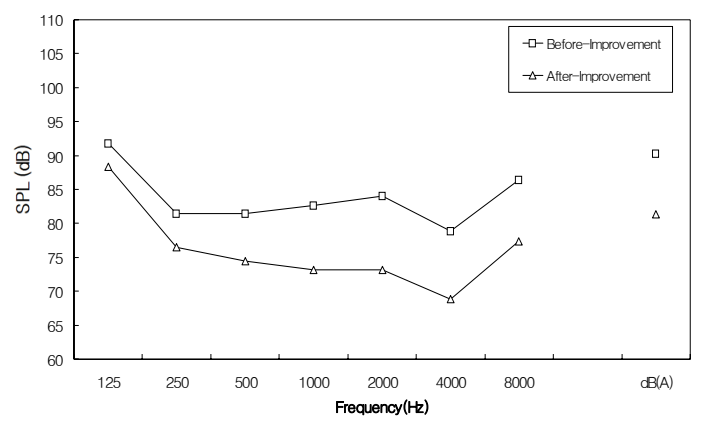

(a) Jewelry processing room

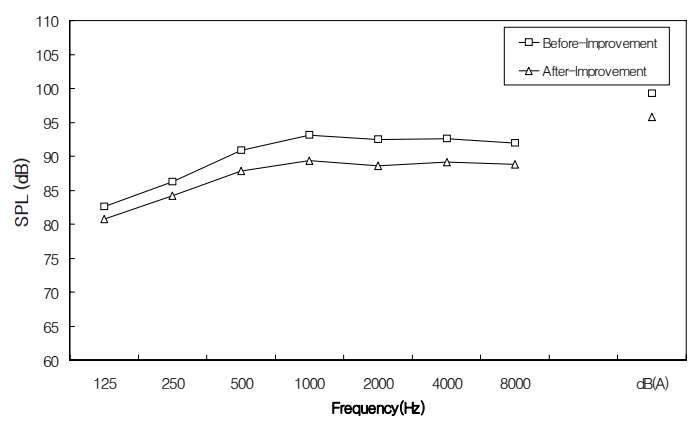

(b) Model making room

Fig. 5 Comparison SPL at before-improvement $\cdot$ afterimprovement
개선 후 많아진 보석 가공장은 $9.1 \mathrm{~dB}(\mathrm{~A})$ 가 감소한 반면, 이보다 흡음되는 면적이 보다 적은 모형 공작 실은 $3.7 \mathrm{~dB}(\mathrm{~A})$ 가 감소하였으나 대상 작업장 모두 소 음이 크게 감소하여 작업자로 하여금 개선 전보다

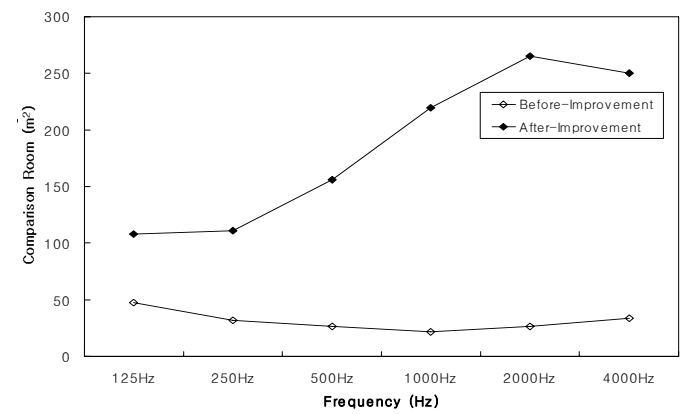

(a) Jewelry processing room

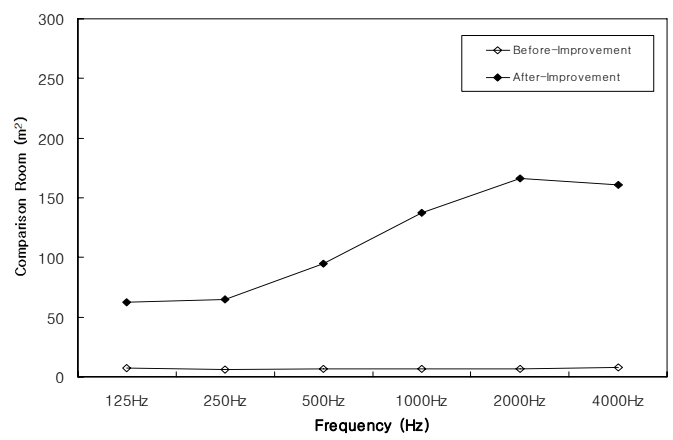

(b) Model making room

Fig. 6 Comparison room constant at before-improvement $\cdot$ after-improvement

Table 8 Comparison SPL at before-improvement $\cdot$ after-improvement $(\mathrm{dB})$

\begin{tabular}{|c|c|c|c|c|c|c|c|c|c|c|}
\hline \multirow{2}{*}{$\begin{array}{l}\text { Loud-noisy } \\
\text { workplace }\end{array}$} & \multirow{2}{*}{\multicolumn{2}{|c|}{ Comparison item }} & \multicolumn{8}{|c|}{ Frequency(Hz) } \\
\hline & & & 125 & 250 & 500 & $1 \mathrm{k}$ & $2 \mathrm{k}$ & $4 \mathrm{k}$ & $8 \mathrm{k}$ & $\mathrm{dB}(\mathrm{A})$ \\
\hline Jewelry & \multirow{4}{*}{$\begin{array}{l}\text { Sound pressure } \\
\text { level } \\
\text { (SPL) }\end{array}$} & Before-improvement & 91.8 & 81.4 & 81.4 & 82.6 & 84.0 & 78.9 & 86.4 & 90.3 \\
\hline $\begin{array}{l}\text { processing } \\
\text { room }\end{array}$ & & After- improvement & 88.3 & 76.5 & 74.4 & 73.1 & 73.2 & 68.8 & 77.4 & 81.2 \\
\hline \multirow{2}{*}{$\begin{array}{l}\text { Model making } \\
\text { room }\end{array}$} & & Before-improvement & 82.6 & 86.2 & 90.9 & 93.1 & 92.5 & 92.6 & 91.9 & 99.3 \\
\hline & & After- improvement & 80.7 & 84.2 & 87.9 & 89.4 & 88.6 & 89.1 & 88.8 & 95.6 \\
\hline
\end{tabular}

Table 9 Comparison room constant at before-improvement $\cdot$ after-improvement $\left(\mathrm{m}^{2}\right)$

\begin{tabular}{|c|c|c|c|c|c|c|c|c|}
\hline \multirow{2}{*}{$\begin{array}{c}\text { Loud- noisy } \\
\text { workplace }\end{array}$} & \multirow{2}{*}{\multicolumn{2}{|c|}{ Comparison item }} & \multicolumn{6}{|c|}{ Frequency(Hz) } \\
\hline & & & 125 & 250 & 500 & $1 \mathrm{k}$ & $2 \mathrm{k}$ & $4 \mathrm{k}$ \\
\hline Jewelry & \multirow{4}{*}{ Room constant } & Before-improvement & 47.4 & 31.8 & 26.5 & 21.7 & 26.4 & 33.7 \\
\hline $\begin{array}{l}\text { processing } \\
\text { room }\end{array}$ & & After-improvement & 107.8 & 110.8 & 155.9 & 219.6 & 265.1 & 250.4 \\
\hline \multirow{2}{*}{$\begin{array}{l}\text { Model making } \\
\text { room }\end{array}$} & & Before-improvement & 7.31 & 5.96 & 6.45 & 6.35 & 6.61 & 7.75 \\
\hline & & After- improvement & 62.3 & 64.6 & 95.1 & 137.5 & 166.4 & 160.8 \\
\hline
\end{tabular}


개선 후 소음으로 인한 피해가 크게 감소할 것으로 사료된다.

\section{(3) 실정수(room constant)}

고소음 작업장의 작업기계에서 발생한 소음은 직 접음과 잔향음 성분으로 구분되어 작업장내의 음압 레벨에 영향을 미친다. 이중 직접음은 기계 자체의 방음대책으로 제어할 수 있지만 잔향음은 실의 마 감 재료를 변경해야만 제어할 수 있다. 따라서 작업 장내에 흡음되는 면적이 적을 경우 내부의 울림이 더욱더 커지기 때문에 소음레벨을 감소시키기 위해 서는 실내의 흡음에 관한 평가지표인 실정수(room constant)를 크게 할수록 좋다. 개선 전-후 연구 대 상 작업장의 마감 재료별 흡음률에 따른 실정수를 비교 분석한 결과는 Table 9와 Fig. 6과 같다.

실정수는 실의 체적과 평균 흡음률에 따라 그 값 을 달리한다. Table 9와 Fig. 6을 보면 음향 시뮬레 이션을 통해 개선 전에 비해 개선 후 흡음력이 높은 마감 재료로 흡음대책을 세운 결과 실내 체적이 $434.72 \mathrm{~m}^{3}$ 인 보석 가공 $500 \mathrm{~Hz}$ 의 실정수가 $26.49 \mathrm{~m}^{2}$ 에서 $155.92 \mathrm{~m}^{2}$ 로, 실내 체적이 $177.5 \mathrm{~m}^{3}$ 인 모형 공 작실은 $6.45 \mathrm{~m}^{2}$ 에서 $95.09 \mathrm{~m}^{2}$ 로 높아졌다. 이러한 결 과로 미루어 볼 때 실정수가 높을수록 잔향음이 흡 수되어 음압레벨이 감소하기 때문에 효율적인 마감 재료를 선정하여 소음을 흡수 하면 고소음 작업장의 소음레벨을 저감시킬 수 있을 것으로 사료된다.

\section{2 가청화를 이용한 개선 전 - 후의 저감효과 평가}

(1) 가청화 음향 시뮬레이션

이 연구에서 사용한 가청화(可聽化)기법은 음향 시뮬레이션을 통해 흡음대책을 한 고소음 작업장의 수음점에서 구한 임펄스 응답(impulse response)과 직접 작업장에서 측정한 작업기계의 음원을 합성연 산(convolution)하여 개선 전과 개선 후의 음향 상 태를 직접 들어 볼 수 있는 방법이며, 가청화의 과 정은 Fig. 7 과 같다.

(2) 청감평가를 위한 평가어휘 조사

이 연구에서는 작업기계 소음에 대해 노출 시 피 험자로 하여금 반응의 정도를 판단하기 위해 선행 연구 결과의 어휘로 구성된 응답지(sheet)를 사용하
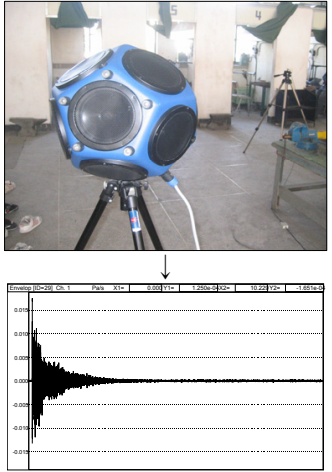

Acoustic property of the loud-noisy workplace

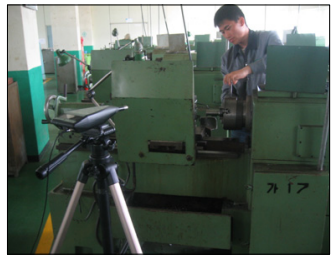

$\downarrow$

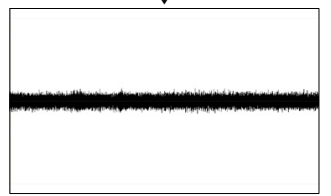

Recording of working machine noise $\hookrightarrow$ Convolution

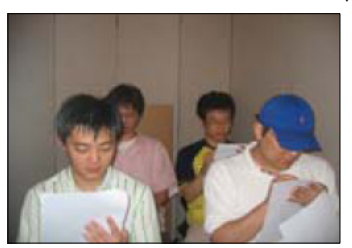

Listening in the anechoic room

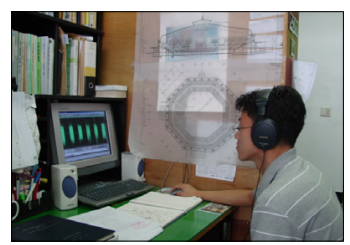

Listening with the headphone
Fig. 7 Auralizational process

Vocabulary : Loud

\begin{tabular}{|lllllllllllll|}
\hline $\begin{array}{c}\text { Not at } \\
\text { all }\end{array}$ & Almost not & Little & A little bit & Noisy & Fairly noisy & $\begin{array}{c}\text { Very much } \\
\text { noisy }\end{array}$ \\
\hline 1 & 2 & 3 & 4 & 5 & 6 & 7 & 8 & 9 & 10 & 11 & 12 & 13 \\
\hline & & & & & & & & & & & \\
\hline
\end{tabular}

Vocabulary : Noisy

\begin{tabular}{|llllllllllll|}
\hline $\begin{array}{c}\text { Not at } \\
\text { all }\end{array}$ & Almost not & Little & A little bit & Noisy & Fairly noisy & $\begin{array}{c}\text { Very much } \\
\text { noisy }\end{array}$ \\
\hline 1 & 2 & 3 & 4 & 5 & 6 & 7 & 8 & 9 & 10 & 11 & 12 \\
\hline
\end{tabular}

Vocabulary : Nervous

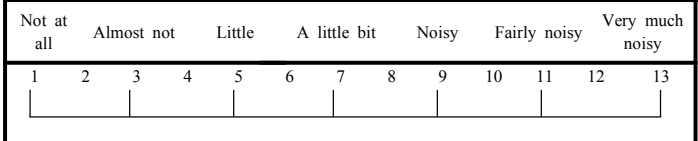

Vocabulary : Unpleasant

\begin{tabular}{|lllllllllllll|}
\hline $\begin{array}{c}\text { Not at } \\
\text { all }\end{array}$ & Almost not & Little & A little bit & Noisy & Fairly noisy & $\begin{array}{c}\text { Very much } \\
\text { noisy }\end{array}$ \\
\hline 1 & 2 & 3 & 4 & 5 & 6 & 7 & 8 & 9 & 10 & 11 & 12 & 13 \\
\hline
\end{tabular}

Vocabulary : Sharp

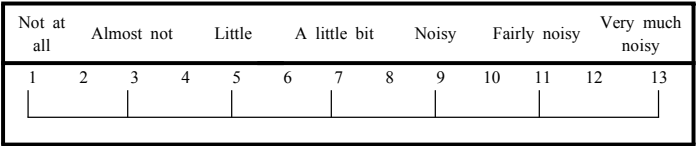

Fig. 8 Psycho-acoustic sheet 


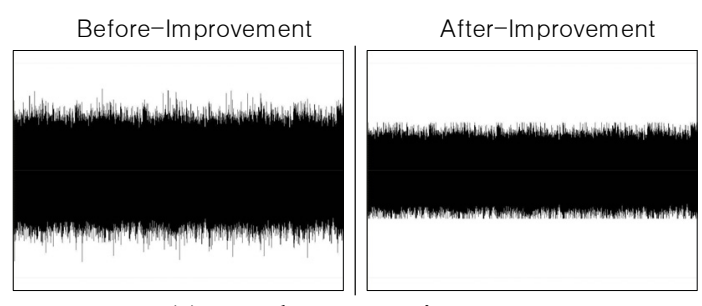

(a) Jewelry processing room
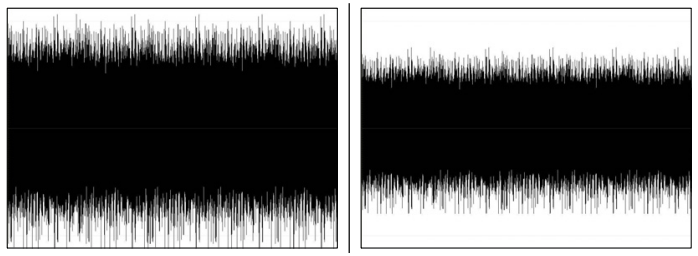

(b) Model making room

Fig. 9 Comparison auralizational sound source from at before-improvement-after-improvement

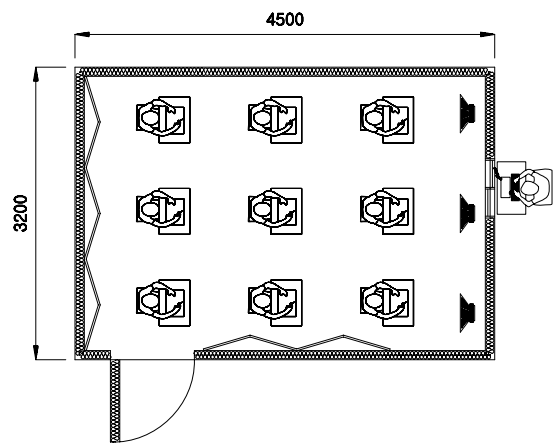

(a) Psycho-acoustics laboratory

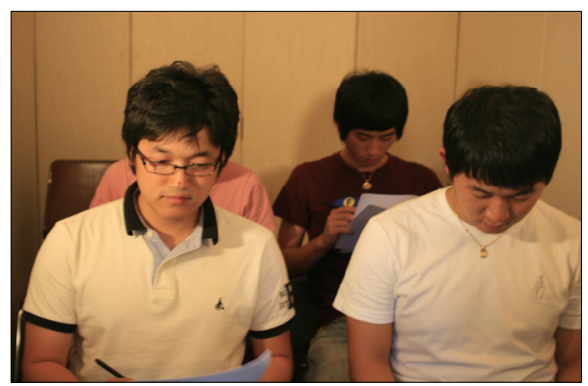

(b) Psycho-acoustics experiment

Fig. 10 Floor plan and experiment scene of psychoacoustics laboratory

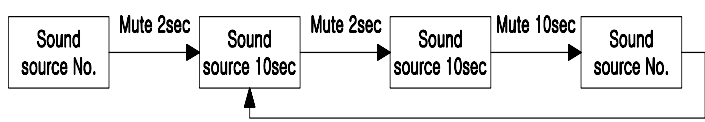

Fig. 11 Presentation process of sound source
였으며, 어휘척도에 따른 반응의 정도는 13 단계 $\mathrm{SD}$ 척도를 이용하였다. 또한 현장성 있는 실험을 위해 설문 전 음원에 해당하는 작업기계를 사진으로 보 여주며 어휘에 대한 설명을 충분히 하였다. 이 연구 에서 사용한 응답지는 Fig. 8과 같다.

\section{(3) 청감평가를 위한 음원의 구성}

청감실험시 사용한 개선 전 음원은 현장에서 녹 음한 각 작업기계의 음원을 합성연산하여 구성하였 으며, 개선 후 음원은 음향시뮬레이션 상에서 가청 화 기법을 이용하여 흡음처리에 의한 음원을 사용 하였다. 또한 이 연구에서 사용된 가청화 음원은 소 음에 대한 최대 피해정도를 알아보기 위해 모든 작 업기계가 동시에 작동한다는 가정하에 음향 시뮬레 이션을 실시하였다. 각 작업기계 별 소음특성을 Cool Edit Pro 2.1을 통해 합성연산한 개선 전·후 의 음원형태는 Fig. 9 와 같다.

(4) 청감평가방법 및 실험

흡음대책 후 변화된 음압레벨 특성을 정확하게 파 악하기 위해 피험자로 선정한 사람은 모두 정상적인 청력을 가진 20 대의 신체 건강한 대학생 및 대학원 생 20 명을 대상으로 하였다. 또한 청감평가를 실시하 기 전 음향에 대한 이해를 돕기 위해 평가시트를 사 전에 나누어 주고 충분한 설명과 함께 반복적으로 음원을 들려준 뒤 실험에 참가하도록 하였다. 실험 장소는 Fig. 10과 같이 무향실과 같은 조건인 원광대 학교 청감실험실(psycho-acoustics chamber)에서 실시 하였다.

음원의 제시 과정은 Fig. 11 과 같으며, 하나의 음 원을 개선 전과 개선 후로 들려주는 방식으로 진행 하였다.

(5) 각 평가어휘에 대한 평균적 반응 항목

대상 고소음 작업장의 개선 전·후의 각 항목별 응답 결과는 Fig. 12 와 같다.

Fig. 12 를 보면 개선 전 보석 가공장의 경우 90.3 $\mathrm{dB}(\mathrm{A})$ 의 높은 음압레벨로 인하여 각 항목의 평균적 반응치가 8.55 11.25의 결과로 높게 나타났으며, 모 형 공작실은 보다 높은 음압레벨인 $99.3 \mathrm{~dB}(\mathrm{~A})$ 로 인하여 각 항목의 평균적 반응치가 $11.95 ~ 12.35$ 의 매우 높은 결과로 나타났다. 또한 모든 항목에 대한 
평균적 반응치가 10 이상을 기록한데 반해 보석 가 공장에서의 “날카롭다" 항목은 8.55 로 나타났다. 이 러한 이유는 인간의 청각은 고주파수에서 민감하게 반응하는데 보석 가공장에 사용하는 대부분의 작업 기계가 모형 공작실에서 사용하는 작업기계에 비해 $2 \sim 8 \mathrm{kHz}$ 의 고주파수 대역에서 음압레벨이 낮기 때 문인 것으로 사료된다.

Fig. 13을 보면 흡음대책을 통한 개선 후 음압레벨 이 $9.1 \mathrm{~dB}(\mathrm{~A})$ 가 감소한 보석가공장의 경우 각 항목의

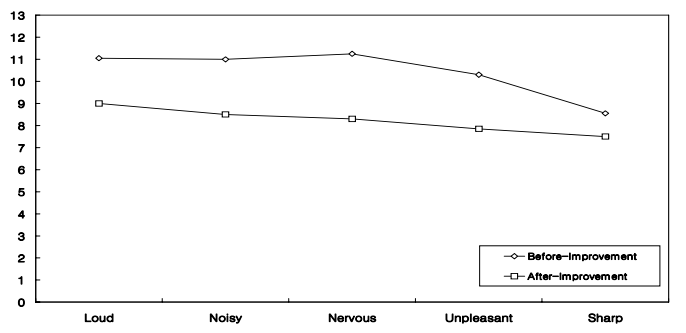

(a) Jewelry processing room

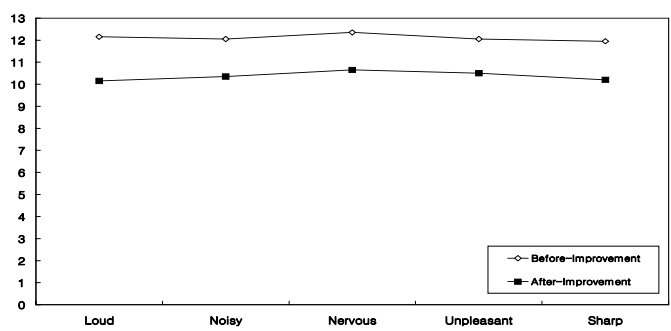

(b) Model making room

Fig. 12 Average reaction about each items through sound-absorption measure at beforeimprovement $\cdot$ after-improvement

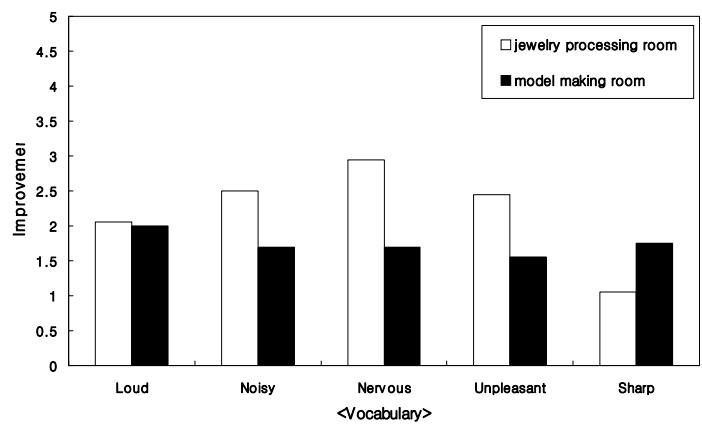

Fig. 13 Improved quantity about each items through sound-absorption measure at before-improvement - after-improvement
평균적 반응치에 따른 개선량은 “크다” 2.05 , “시끄 럽다" 2.50, “신경쓰인다" 2.95, “불쾌하다” 2.45 , "날카롭다" 1.05 로 나타났으며, $3.7 \mathrm{~dB}(\mathrm{~A})$ 가 감소한 모형 공작실은 “크다” 2.00, “시끄럽다” 1.70, “신 경쓰인다" 1.70 , “불쾌하다" 1.55 , “날카롭다" 1.75 정도 개선되었다. 이러한 결과로 미루어 볼 때 고소 음 작업장을 흡음재로 마감하여 고소음을 저감 할 수 있는 방법이 매우 실효성 있을 것으로 사료된다.

(6) 대상 고소음 작업장의 개선 정도 비교 분석 가청화를 실시한 대상 고소음 작업장의 전체적인 주관적인 인상을 알아보기 위해 평가 어휘별로 대 상 고소음 작업장의 대한 개선 전·후의 빈도분석결 과를 정규분포곡선으로 나타낸 것은 Fig. 14와 같다.

Fig. 14를 보면 대상 고소음 작업장에서 사용하는 작업기계가 매우 높은 음압레벨을 발생시켜 모든 항 목들이 높게 평가 되었으나 잔향음을 제어하는 흡음 대책을 통해 고소음 작업장의 소음대책을 강구한 개 선 후의 경우 실험에 참가한 피험자들로 하여금 작 업장 소음환경 개선에 대해 매우 긍정적인 반응을

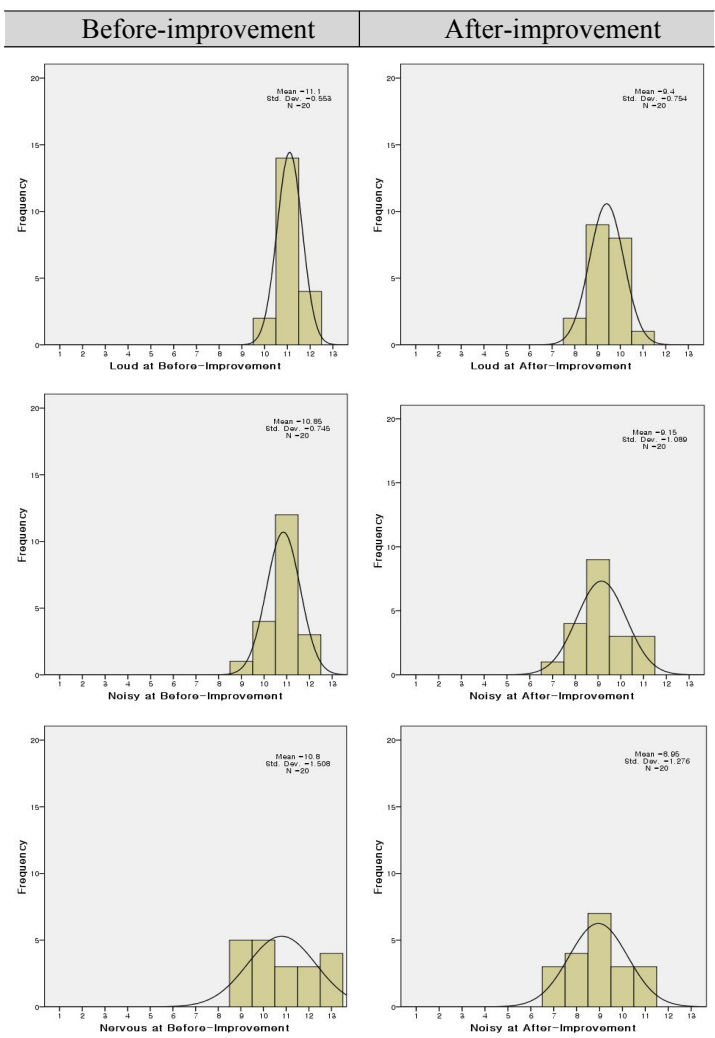



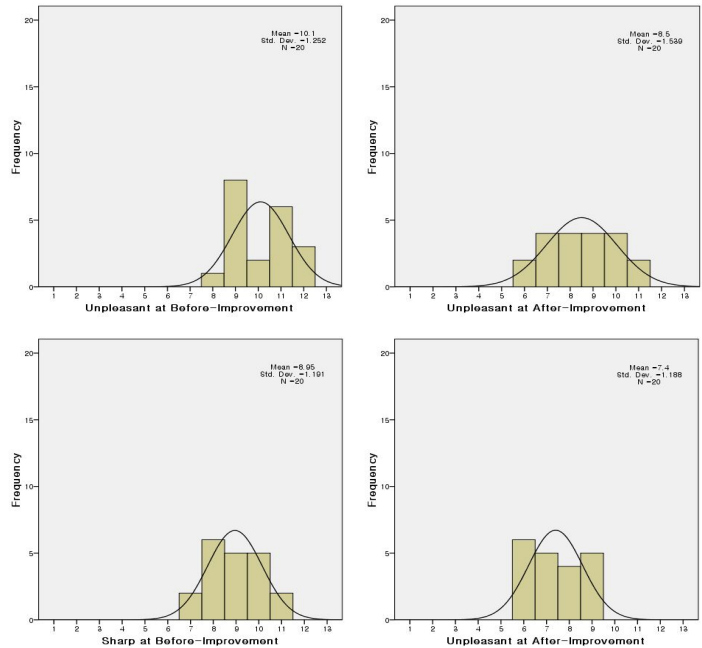

(a) Jewelry processing room
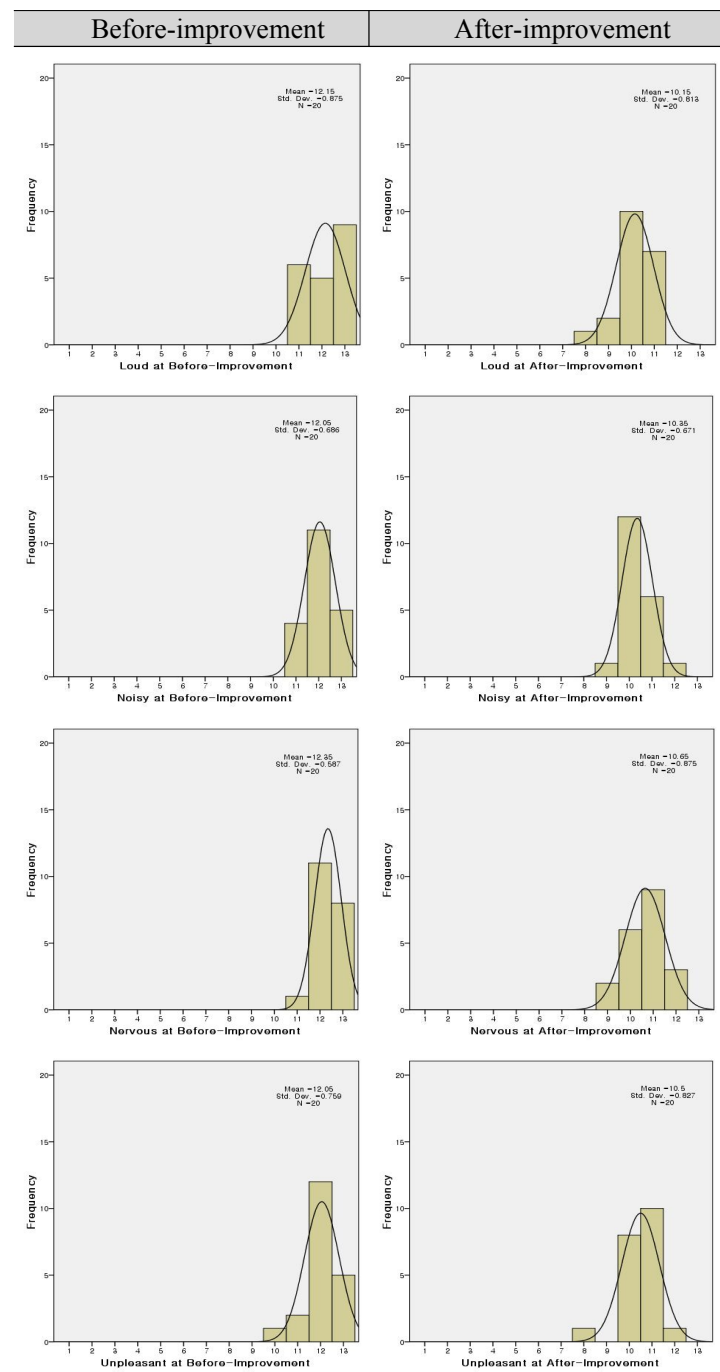
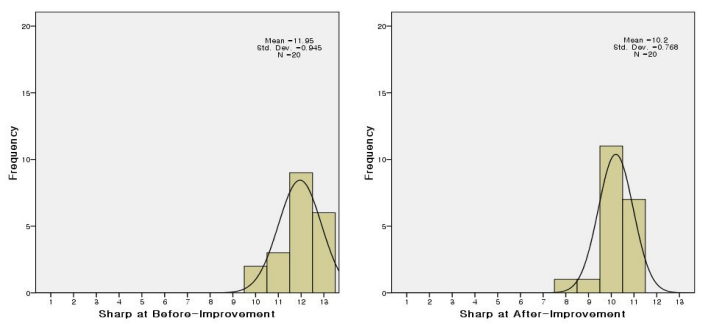

(b) model making room

Fig. 14 Frequency analysis, after-improvement(normal distribution curve)

보이는 것으로 나타났다. 만약 이와 같은 흡음대책 과 함께 직접음에 해당하는 작업기계 자체의 방음 대책을 강구 한다면 소음에 대해 보다 더 긍정적인 반응을 보일 것으로 사료된다.

\section{4. 결 론}

이 연구는 고소음 작업장 소음대책의 방안으로 음향 시뮬레이션 기법을 이용하여 실측치와 예측치 의 신뢰성을 검토한 후 흡음대책을 통해 작업장 소 음의 개선정도를 예측해 보았으며, 가청화 청감실험 을 실시한 결과는 다음과 같다.

(1) 고소음 작업장별로 실측된 잔향시간을 동일 하게 모델링한 음향 시뮬레이션상의 예측값과 비교 한 결과 주파수 별로 거의 유사한 패턴을 보였다. 또한 cronbach's $\alpha$ 계수가 보석 가공장은 0.950 , 모형 공작실은 0.972 의 높은 신뢰도로 나타나 시뮬 레이션을 이용한 예측치의 신뢰성을 확보할 수 있 었다.

(2) 음향 시뮬레이션을 기법을 이용하여 흡음대 책을 통한 음압레벨의 개선 전·후 결과 전 주파수에 걸쳐 음압레벨이 감소하였으며, 음압레벨의 경우도 보석 가공장은 $9.1 \mathrm{~dB}(\mathrm{~A})$, 모형 공작실은 $3.7 \mathrm{~dB}(\mathrm{~A})$ 가 감소하여 고소음 작업장의 소음이 크게 개선된 것을 알 수 있었다. 또한 $500 \mathrm{~Hz}$ 실정수의 개선 전. 후 결과 보석 가공장은 $26.49 \mathrm{~m}^{2}$ 에서 $155.92 \mathrm{~m}^{2}$ 로, 모형 공작실은 $6.45 \mathrm{~m}^{2}$ 에서 $95.09 \mathrm{~m}^{2}$ 로 실정수가 높아졌다. 따라서 실정수가 높을수록 발생하는 내부 소음이 흡수되어 음압레벨이 감소하기 때문에 효율 적인 흡음 대책을 통한 고소음 작업장의 소음대책 
이 앞으로는 매우 중요 할 것으로 사료된다.

(3) 가청화 청감평가 결과 개선 전에는 작업기계 의 높은 음압레벨로 인하여 보석 가공장은 각 항목 의 평균치가 $8.55 \sim 11.25$, 모형 공작실은 11.95 12.35 의 매우 높은 결과로 나타났다. 그러나 흡음대 책을 통한 개선 후 보석 가공장은 각 항목의 평균 치에 따른 개선량이 $1.05 \sim 2.95$, 모형 공작실은 1.55 2가 감소하게 나타났다. 따라서 이러한 결과로 미루어 볼 때 고소음 작업장을 흡음재로 마감하여 고소음을 저감 할 수 있는 방법이 매우 실효성 있 을 것으로 사료된다. 또한 이와 같은 흡음대책과 함 께 직접음에 해당하는 작업기계 자체의 방음대책을 강구 한다면 소음에 대해 작업자로 하여금 보다 더 쾌적한 업무환경 수립이 가능할 것으로 사료된다.

이 연구 결과에서 제시한 흡음대책을 통하여 대 상 고소음 작업장의 작업환경을 개선 한다면 작업 자로 하여금 보다 더 쾌적한 작업장 환경 수립이 가능할 것으로 사료된다. 또한 이 연구와 유사한 다 른 연구들이 지속된다면 고소음 작업장의 소음저감 대책 시 유용한 자료로 활용될 수 있을 것으로 사 료된다.

\section{참 고 문 헌}

(1) Kook, J. H., Jung, C. W., Jung, E. J. and Kim, J. S., 2006, "A Study on the Evaluation and
Characteristics of Plumbing Noise in Building," Proceedings of The AIK '06 Autumn Annual Conference pp. 673 676.

(2) Kim, J. S., 2007, Architectural Acoustic Design (3rd edition), Sejin Co.

(3) Evaluation Technique on Architectural Acousic Performance Using Auralization, Acoustical Materials Association of Korea, Vol. 3, Acoustic Material Technology, 2007.8

(4) Yoon, J. H., Choi, D., Kim, J. S., 2008, “A Study on Characteristics of Noise generates when Jewelry-Processing," Proceedings of the KSNVE Annual Autumn Conference, pp. 417 418.

(5) Yoon, J. H., Kim, D. G., Kim, J. S., 2008, "A Study on Property of Machinery Noise Generates at Model Workshop," Proceedings of the Korean Society of Environmental Engineers, p.171.

(6) Joo, D. H., Kook, J. H., Kim, J. S., 2007, "Typical of Vocabulary for Evaluation on InstrumentNoise Generates at Loud Noisy Workplace," Proceedings of the KSNVE Annual Autumn Conference, KSNVE07A-10-16.

(7) Yoon, J. H., Choi, D., Kim, J. S., 2008, “A Study on Sound-absorption Measure Using Acoustic Simulation for Loud-noisy Workplace," Proceedings of the KSNVE Annual Autumn Conference, pp. 619 620. 